\title{
Viscoelastic Properties in Cancer: From Cells to Spheroids
}

\author{
Yara Abidine ${ }^{\dagger} \ddagger$, Arianna Giannetti $\ddagger$, Jean Revilloud, Valérie M. Laurent and Claude Verdier *D \\ Université Grenoble Alpes, CNRS, LIPhy, F-38000 Grenoble, France; yara.abidine@gmail.com (Y.A.); \\ argianna21@gmail.com (A.G.); jean.revilloud@univ-grenoble-alpes.fr (J.R.); \\ valerie.laurent@univ-grenoble-alpes.fr (V.M.L.) \\ * Correspondence: claude.verdier@univ-grenoble-alpes.fr; Tel.: +33-4-7663-5980 \\ † Current address: Virology Group, Clinical Microbiology Department, Umeå University, 90187 Umeå, Sweden. \\ $\ddagger$ These authors contributed equally to this work.
}

check for

updates

Citation: Abidine, Y.; Giannetti, A.; Revilloud, J.; Laurent, V.M.; Verdier, C. Viscoelastic Properties in Cancer: From Cells to Spheroids. Cells 2021, 10, 1704. https://doi.org/10.3390/ cells10071704

Academic Editor: Nicoletta Gagliano Received: 4 June 2021

Accepted: 30 June 2021

Published: 6 July 2021

Publisher's Note: MDPI stays neutral with regard to jurisdictional claims in published maps and institutional affiliations.

\begin{abstract}
AFM-based rheology methods enable the investigation of the viscoelastic properties of cancer cells. Such properties are known to be essential for cell functions, especially for malignant cells. Here, the relevance of the force modulation method was investigated to characterize the viscoelasticity of bladder cancer cells of various invasiveness on soft substrates, revealing that the rheology parameters are a signature of malignancy. Furthermore, the collagen microenvironment affects the viscoelastic moduli of cancer cell spheroids; thus, collagen serves as a powerful proxy, leading to an increase of the dynamic moduli vs. frequency, as predicted by a double power law model. Taken together, these results shed new light on how cancer cells and tissues adapt their viscoelastic properties depending on their malignancy and the microenvironment. This method could be an attractive way to control their properties in the future, based on the similarity of spheroids with in vivo tumor models.
\end{abstract}

Keywords: cancer cells; spheroids; AFM; confocal microscopy; rheology; microenvironment

\section{Introduction}

Cell mechanical properties are essential in various processes such as cell migration, embryogenesis, wound healing, and the immune response, i.e., physiological processes, but also in various pathological cases, in particular during cancer metastasis. Understanding how cell deformability can control the way cancer cells migrate or extravasate through blood vessels is essential. While it is well known that the elastic properties play a central role in such processes [1,2], the viscoelastic nature of the cell system is significant and has to be taken into account [3-5]. The many filaments (actin, microtubules, and intermediate filaments) of the cell provide a rigid structure to the cell, thus an elastic response, and the surrounding fluid embraces viscosity, providing the typical viscoelastic nature of the cell, similar to a physical gel that can remodel constantly. This is indeed what is happening as the cell migrates, and F-actin filaments polymerize at the front to push the membrane forward, while the other actin monomers are recycled [6]. Several other studies have proposed a different behavior for the cell cytoplasm, where the fluid flow can affect the mechanical response and give rise to a poroelastic behavior $[7,8]$. It is therefore important to obtain experimental data regarding cell behavior under various mechanical solicitations such as constant force, prescribed deformation, or rate of deformation. For this reason, new methods have been proposed to determine such properties, either locally using AFM [9,10], magnetocytometry [11], particle-tracking measurements [12], or using global measurements thanks to microfluidics [13], micropipettes [14], optical tweezers [15], or optical coherence elastography [16].

While the mechanical properties of cancer cells have been extensively studied $[1,2,5]$, the tissue scale is less known; therefore the aim of this work was to understand how cellular properties combine and whether similar ones are retained at a higher scale. As could be 
expected, several features are preserved as classical tissues follow nonlinear elastic behaviors with a substantial role of the deformation rate [17]. Tissues are usually made of cells surrounded by the extra cellular matrix (ECM) inside a fluid, and the concentrations of the different components depend on tissue type. Cell suspensions have been described $[18,19]$ using mixture models and exhibit a behavior close to that of yield stress fluids, when the cell concentration is around $50 \%$ or more. On the other end, with a large collagen content [20] and a small amount of cells (around 10\%), the behavior becomes viscoelastic, but the effect of cells on the ECM is critical, since cells are able to remodel the collagen network.

To investigate other biological tissues-in particular solid tumors-spheroids have been developed over the years [21] and are considered to be outstanding in vitro models for the investigation of tumors. They are made of cells closely packed together, surrounded by the ECM in culture medium. Spheroids can grow and make their own ECM, and cell adhesion molecules (cadherins in particular) can form to bind cells within the spheroid afterwards. Several earlier studies have focused on the role of compressive stresses exerted from the outside onto the tumor [22,23], with a limiting effect on growth. Fewer results are devoted to the understanding of the mechanical behavior of such spheroids, but recent models have focused on the flow of the interstitial liquid within the spheroids [21] and revealed that poroelastic active models can fully describe them [24]. These effects have also been observed on other tissues such as cartilage or tendons, revealing notable high-frequency poroelastic responses $[25,26]$, which can be used to differentiate physiological and pathological tissues. Although these systems are different, possible correlations can be made.

In this work, AFM was chosen as an interesting device to probe both single cancer cells and spheroids made of the same cells. A microrheology method was developed based on initial indentation followed by oscillations at various frequencies $[5,27]$, to probe the viscoelastic properties of cells and spheroids. The method is presented in Section 3 together with the modeling tools and is used further on different cells in different environments (Section 4). Then, the model was adapted to spheroids, and similar data were obtained (Section 5); however, some differences between the two systems investigated were observed: the viscoelastic properties of both cells and spheroids depend on the microenvironment (substrate or collagen within the spheroid). Therefore, complementary confocal microscopy experiments were carried out on the spheroids to understand these behaviors, and all results are discussed in Section 6.

\section{Materials and Methods}

\subsection{Cancer Cells}

Three epithelial bladder cancer cell lines with increasing malignancy were used: RT112 (luminal molecular subtype, Leibniz Institute DSMZ, Braunschweig, Germany) and T24 and J82 (American Type Culture Collection, Manassas, VA). RT112 is a moderately differentiated cell line that exhibits low invasiveness, while T24 and J82 are both poorly differentiated and very malignant cells, with J82 being the more invasive type. The choice of such bladder cell lines came from earlier studies by the authors [28-31], and the classification method was described previously [27]. These cells were cultured in RPMI 1640 (Gibco, Saint-Aubin, France) supplemented with 10\% fetal bovine serum (FBS, Life Technologies SAS, Villebon-sur-Yvette, France) and 1\% penicillin-streptomycin (Life Technologies SAS). One day before the measurements, cells were seeded at a low density on polyacrylamide gels coated with $20 \mathrm{mg} / \mathrm{mL}$ fibronectin (PromoCell, Heidelberg, Germany) overnight at $37^{\circ} \mathrm{C}$ in a humidified $5 \% \mathrm{CO}_{2}$ atmosphere. These cells are considered to adhere firmly on such gels. AFM measurements were carried out on isolated cells at $37^{\circ} \mathrm{C}$. These cells were stably transfected with a plasmid expressing LifeAct-GFP to stain F-actin according to a previous work [32]. Results were collected on a reasonable number of cells in various conditions $(\mathrm{N}=5)$, which can be used to extract statistical significance. More data are available in our other works $[5,27]$. 


\subsection{Polyacrylamide Gels}

Two-dimensional polyacrylamide gel substrates were prepared prior to seeding of cells using a previous protocol [27]. These gels were synthesized by mixing acrylamide (30\% w/w) and N-hydroxyethyl-acrylamide (5.85\% $w / w)$ at fixed concentrations of $3.2 \%$ and $1.25 \%$, respectively, as well as $\mathrm{N}, \mathrm{N}$-methylene-bisacrylamide $(2 \% w / w)$ at three different weight concentrations $(0.1-0.3-0.6 \%)$ in a $50 \mathrm{mM}$ HEPES buffer. After the gels were degassed for $20 \mathrm{~min}$, polymerization was initiated using 10\% ammonium persulfate solution (APS) and $\mathrm{N}, \mathrm{N}, \mathrm{N}^{\prime}, \mathrm{N}^{\prime}$-tetramethylethylenediamine (TEMED). All reagents were from Sigma-Aldrich. The rigidity of the gels was modulated using the three above bisacrylamide concentrations to reach gel rigidities of 5,8 , and $28 \mathrm{kPa}$, as measured by AFM. Functionalization was then achieved using fibronectin $(20 \mu \mathrm{g} / \mathrm{mL})$ for one hour at room temperature. Gels were kept under humid conditions before cells were seeded.

\subsection{Spheroids' Preparation}

Spheroids can be made of various cells inside an extracellular matrix and are reported to be good candidates for modeling tumors. This is why the same T24 cells as above were selected to prepare them. As before, T24 cells were cultured in RPMI 1640 medium supplemented with $10 \%$ FBS and 1\% penicillin-streptomycin. Ninety-six-well plates were filled with a 1.5\% sterile agarose solution (Abnova, Fischer Scientific, Illkirch, France), which solidified quickly at room temperature. Then, ten-thousand cells were added into the well. Finally, type I rat tail collagen (Corning, Bedford, MA, USA) at a 0.01 or $0.03 \mathrm{mg} / \mathrm{mL}$ concentration $\left(4^{\circ} \mathrm{C}\right.$ and $\left.\mathrm{pH} \sim 7.4\right)$ was added to the medium, since collagen is a good model to mimic the microenvironment of bladder cancer cells [33]. The 96-well plate was centrifuged for $10 \mathrm{~min}$ at $200 \times \mathrm{g}$. Cells remained at the bottom of the well and were followed in time. After 3 days, spheroids usually presented a spherical, compact shape. Experiments were conducted then, with the spheroid diameter $D$ ranging between 270 and $400 \mu \mathrm{m}$. Spheroids were detached with a $100 \mu \mathrm{L}$-pipette (chopped nozzle) and deposited into Petri dishes (TPP, to fit within the AFM setup) in culture medium. Up to three spheroids could be measured at the same time. After sedimentation and proper adhesion to the Petri dish bottom, the AFM cantilever was lowered to come into contact with the top of the spheroid, and measurements were carried out as explained below (Section 3.2). Results were collected for $\mathrm{N}=15,10$, and 6 for the respective collagen concentrations of $0,0.01$, and $0.03 \mathrm{mg} / \mathrm{mL}$, with spheroid sizes ranging from $300 \mu \mathrm{m}$ to $410 \mu \mathrm{m}$.

\subsection{Confocal Microscopy of Spheroids}

Confocal imaging of spheroids containing $0.01 \mathrm{mg} / \mathrm{mL}$ collagen was carried out using a confocal Leica TCS SP8 (LIPhy platform). Cells with F-actin GFP labeling were imaged in the green channel (argon laser, $488 \mathrm{~nm}$ ), and collagen was imaged using the reflectance technique in the red channel (HeNe laser, $633 \mathrm{~nm}$ ) [20,34]. The spheroids were prepared as described earlier and allowed to sediment in a Petri dish (with a $170 \mu \mathrm{m}$ glass coverslip bound to the bottom). Images were taken ( $40 \times$ Leica oil-objective) from the bottom to the median part, as it was difficult to penetrate deeper than $200 \mu \mathrm{m}$. Z-stacks were acquired using steps of $0.35 \mu \mathrm{m}$. Then, images were processed using the Fiji software.

\subsection{Statistical Analysis}

Statistical analysis was measured using a two-sample unpaired Student's $t$-test. Statistical significance was reached for ${ }^{*} p<0.05$ and ${ }^{* *} p<0.01$, while $p>0.05$ was considered nonsignificant. Means are presented with the standard error of the mean (SEM).

\section{Microrheology Using AFM}

\subsection{Principles of Viscoelasticity}

The main idea behind viscoelasticity comes from the combined properties of soft systems under applied deformations or forces. When the system is elastic, stresses (i.e., 
forces per unit surface, in $\mathrm{Pa}$ ) are proportional to deformations, whereas a viscous material will flow under an applied force, with stresses proportional to the rate of deformation. In order to capture both viscous and elastic responses, one can apply a sinusoidal shear deformation $\delta=\delta_{0} \sin (\omega t)$, where $\delta_{0}$ is the amplitude of the deformation and $\omega=2 \pi \mathrm{f}$ is the angular frequency ( $\mathrm{f}$ is the frequency in $\mathrm{Hz}$ ). At small enough deformations $\delta_{0}$, one can assume and check $[5,10,35]$ that the shear stress response is also periodic in time $\tau(t)=\tau_{0} \sin (\omega t+\phi)$ at the same angular frequency, where $\tau_{0}$ is the stress amplitude and where $\phi$ is a phase shift. Thus, one can extract the components of stress in phase $(\phi=0)$ and phase opposition ( $\phi=\pi / 2$ ), i.e., the moduli $\mathrm{G}^{\prime}$ (elastic) and G" (viscous or loss), which appear as the coefficients in front of the $\sin (\omega t)$ and $\cos (\omega t)$ terms. It was found that $G^{\prime}=\tau_{0} \cos \phi / \delta_{0}$ and $G^{\prime \prime}=\tau_{0} \sin \phi / \delta_{0}$. The resulting complex $G^{*}=\frac{\sigma^{*}}{\delta^{*}}=G^{\prime}+i G^{\prime \prime}$ is called the complex shear modulus, and the loss angle $\phi$ is defined by $\tan \phi=\frac{G^{\prime \prime}}{G^{\prime}}$, as the ratio of viscous to elastic stresses. Given these basic principles, let us now consider a real experiment based on the use of an AFM.

\subsection{Oscillations Using an AFM}

AFM experiments were carried out using a Nanowizard II AFM (JPK Instruments) mounted on a Zeiss microscope (Observer D1). AFM is based on the use of a tip placed on a cantilever that can be set in contact with a surface to investigate the forces due to the interactions between the tip and the substrate. The laser reflected by the cantilever onto a photodiode gives the tip displacement and therefore the force thanks to proper calibration. Calibration was performed here for the sensibility parameter ( $s \sim 30-80 \mathrm{~nm} /$ Volt $)$, then using the thermal fluctuation method [36] to finally obtain the cantilever stiffness ( $\mathrm{k}$ in $\mathrm{N} / \mathrm{m}$ ). In this study, we used soft cantilevers (MLCT, lever C, Bruker, Billerica, CA) with stiffness on the order $k \sim 0.01 \mathrm{~N} / \mathrm{m}$ for cells, whereas for spheroids, stiffer cantilevers (Nanosensors, TL-NCL model) were favored, with $\mathrm{k} \sim 30 \mathrm{~N} / \mathrm{m}$. The basic idea is to perform an initial indentation $\delta_{0}$, then to superimpose small sinusoidal deformations $\delta$ at a given frequency $f$. For cells, we started from the Sneddon relationship [37] for pyramidal tips, where the applied force $F_{0}$ is related to the indentation $\delta_{0}$ by: $F_{0}=\frac{3}{4} \frac{E \tan \theta \delta_{0}^{2}}{1-v^{2}}$, where $E$ is the elastic Young's modulus, $v$ is the Poisson ratio $(\nu \sim 0.5)$, and $\theta$ is the half-pyramid angle. This relationship is then linearized (assuming $\delta \ll \delta_{0}$ ), to obtain:

$$
G^{*}(\omega)=G^{\prime}+i G^{\prime \prime}=\frac{1-v}{3 \tan \theta \delta_{0}}\left\{\frac{F^{*}(\omega)}{\delta^{*}(\omega)}-i \omega b(0)\right\}
$$

The final calibration regards the hydrodynamic drag created by oscillations of the cantilever in a fluid: the drag is proportional to viscosity and velocity, but also depends on geometry. Here, the geometry of the cantilever was different each time, so the best way to calibrate it was to oscillate far from the substrate (given distance $h$ ), then come closer to it $(\mathrm{h} \sim 0)$. The drag force is a pure imaginary number $F^{*} / \delta^{*}=i \omega b(h)$, where $b(h)$ is to be found. Using the method suggested by Alcaraz et al. [38], we found that $b(0)=6.95 \times 10^{-6} \mathrm{~N} . \mathrm{s} / \mathrm{m}$ for the MLCT cantilevers that we used in a typical culture medium.

In the case of spheroids, another method was proposed using large tipless cantilevers [35] indenting the spherical aggregate. The flat cantilever indented the spheroid with initial indentations $\delta_{0} \sim 4-8 \mu \mathrm{m}$, corresponding to contact radii $\sim 20-40 \mu \mathrm{m}$, and an area of contact $\sim 1200-5000 \mu \mathrm{m}^{2}$. As cells were connected to each other, indentation operated over the whole spheroid, as it is known from continuum theory that a soft substrate plays a role in the measured apparent modulus [27]. The Hertz formula was now applied in a reverse manner (i.e., the rigid cantilever was in contact with the soft spheroid) and led to $F_{0}=\frac{4}{3} \frac{E \sqrt{R} \delta_{0}^{3 / 2}}{1-v^{2}}$. After linearization, one finds:

$$
G^{*}(\omega)=G^{\prime}+i G^{\prime \prime}=\frac{1-v}{4\left(R \delta_{0}\right)^{1 / 2}}\left\{\frac{F^{*}(\omega)}{\delta^{*}(\omega)}-i \omega b(0)\right\}
$$


where $R$ is the spheroid radius and the other parameters remain unchanged. In that case, the hydrodynamic drag calibration gave $b(0)=3.45 \times 10^{-5} \mathrm{~N} . \mathrm{s} / \mathrm{m}$.

Therefore, using this method, it was possible to obtain the viscoelastic data $\left(G^{\prime}, G^{\prime \prime}\right)$ over a large range of frequency, ranging from $1 \mathrm{~Hz}$ to $1 \mathrm{kHz}$.

\subsection{Substrate Effects}

Investigating cells in a complex environment demands evaluating the mechanical properties of the surrounding media or tissues. Typically, the values of soft tissues (excluding bones) range from $50 \mathrm{~Pa}$ to $20 \mathrm{kPa}$. Therefore, our studies focused on such media. When using AFM on cells plated on a soft/rigid substrate, it is important to account for its rigidity. Indeed, the cell apparent modulus is overestimated on a rigid substrate, but can be estimated for different cantilever geometries $[39,40]$. On the other hand, less is known about soft substrates, where the apparent modulus can be underestimated, as shown recently [27,41,42]. This is precisely what was done prior to this study. The details of the calculations can be found in our previous work [27]. Corrections made use of an equivalent medium made of the glass substrate covered by a thick gel, on top of which cells were deposited. This medium was described by a simple apparent modulus [43], and Equation (1) is modified as shown previously [27] to obtain the corrected moduli $\left(G^{\prime}, G^{\prime \prime}\right)$.

\subsection{Rheological Model}

Different authors have tried to model viscoelastic data. Previous studies reported that polymers or complex materials $[44,45]$ exhibiting wide relaxation spectra have a power law dependence, i.e., moduli $G^{\prime}$ and $G^{\prime \prime}$ vary with a certain power of the frequency (f). For example, it was reported that cells have moduli $\left(G^{\prime}, G^{\prime \prime}\right)$ varying with the same small exponents $\sim 0.1-0.3$ and behave as Newtonian fluids at higher frequencies [10]. Nevertheless, a single exponent is usually not enough to cover the whole frequency range; therefore, it is better to define different frequency domains with different exponents $[5,27,46]$. This is what was done here. Assuming that both moduli exhibit two different behaviors according to the frequency range, as shown in Figure 1, a double power law behavior can be assumed, of the following form:

$$
G^{\prime}=G_{0}\left(\frac{f}{f_{0}}\right)^{a}+G_{1}\left(\frac{f}{f_{0}}\right)^{b}, \quad G^{\prime \prime}=G_{2}\left(\frac{f}{f_{0}}\right)^{c}+G_{3}\left(\frac{f}{f_{0}}\right)^{d}
$$
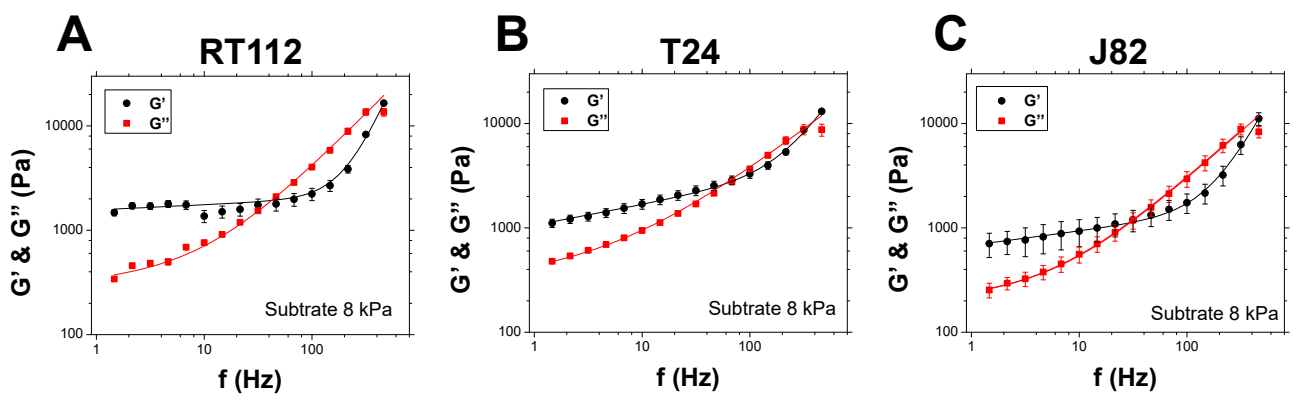

Figure 1. Viscoelastic moduli of RT112, T24, and J82 cells on an $8 \mathrm{kPa}$ substrate. The elastic modulus $G^{\prime}$ (black) and the loss modulus $G^{\prime \prime}$ (red) are shown as a function of frequency $f$. These measurements were performed above the cell nucleus. The lines correspond to the model in Equation (3), using (A) $G_{0}=1567 \mathrm{~Pa}, \mathrm{a}=0.05, \mathrm{G}_{1}=0.005 \mathrm{~Pa}, \mathrm{~b}=2.4, \mathrm{G}_{2}=321 \mathrm{~Pa}, \mathrm{c}=0.07, \mathrm{G}_{3}=29.4 \mathrm{~Pa}, \mathrm{~d}=1.05$, (B) $G_{0}=1060 \mathrm{~Pa}, \mathrm{a}=0.20, G_{1}=0.24 \mathrm{~Pa}, \mathrm{~b}=1.7, G_{2}=351 \mathrm{~Pa}, \mathrm{c}=0.08, \mathrm{G}_{3}=84 \mathrm{~Pa}, \mathrm{~d}=0.8$ and (C) $G_{0}=682 \mathrm{~Pa}, \mathrm{a}=0.14, \mathrm{G}_{1}=0.04 \mathrm{~Pa}, \mathrm{~b}=2, \mathrm{G}_{2}=205 \mathrm{~Pa}, \mathrm{c}=0.01, \mathrm{G}_{3}=40 \mathrm{~Pa}, \mathrm{~d}=0.92$. $\mathrm{N}=5$; error bars represent the mean \pm the standard error of the mean (SEM).

Note that we used $f_{0}=1 \mathrm{~Hz}$, and $f$ is expressed in Hz. By making this dimensionless reduction, we can get rid of the complex units. Indeed, $G_{0}, G_{1}, G_{2}, G_{3}$ are simply expressed in Pascals (Pa), whereas exponents $a, b, c, d$ are dimensionless. We note further that: 
- A plateau for $G^{\prime}$ is sometimes obtained at low frequencies (see Figure $3 \mathrm{~A}$ below), so that $a=0$, and $G_{0}$ is the so-called elastic plateau modulus [5];

- A single power law for $G^{\prime}$ can be enough to describe the data (see Figure 3B for instance), then $G_{1}=0$;

- Note that for low frequencies, when the second term is negligible, $G^{\prime} \sim G_{0}\left(\frac{f}{f_{0}}\right)^{a}$ and $G^{\prime \prime} \sim G_{2}\left(\frac{f}{f_{0}}\right)^{c}$ so that $G_{0} \sim G^{\prime}(1 \mathrm{~Hz})$ and, similarly, $G_{2} \sim G^{\prime \prime}(1 \mathrm{~Hz})$;

- We also recovered most of the cases studied before; in particular, Alcaraz et al. [10] found $G_{1}=0, a=c$ and $d=1$ for single cells;

- In general, when two slopes are visible [46], two parameters are enough to capture the frequency dependence of the moduli (Figure 1 and Figure 3).

\section{Results on Live Cancer Cells}

\subsection{Cell Viscoelastic Properties}

The viscoelastic properties of the three different cell lines with increasing invasiveness (RT112 < T24 < J82) were measured using AFM as described in Section 3.2. The measurements were located above the cell nucleus with a maximum indentation of the AFM tip of $500 \mathrm{~nm}$. Cells adhered on gels of different rigidities, and the contribution of the substrate to the viscoelastic properties was corrected as described in Section 3.3, ensuring that only the microrheology of the cells was characterized. This correction was essential as it allowed the comparison between different cell lines. Figure 1 shows the elastic modulus $G^{\prime}$ (black) and the loss modulus $G^{\prime \prime}$ (red) of cells adhering on a soft gel of $8 \mathrm{kPa}$ (with stiffness similar to an endothelial monolayer [27]). First, one can observe that the viscoelastic properties followed a common behavior with $G^{\prime}$ and $G^{\prime \prime}$ increasing with frequency with the ratio of $G^{\prime \prime} / G^{\prime}$ when the invasiveness increased, suggesting an effect of the invasiveness on the microrheology of cancer cells. Moreover, the elastic modulus of the less invasive cells RT112 revealed a plateau modulus at the lower frequencies (Figure 1A), which was not present for T24 and J82 (Figure 1B,C), indicating that invasiveness had the effect of making cells less elastic.

The quantitative parameters of cancer cell microrheology were then found using the model in Equation (3) and are summarized in Figure 2 and Figure S1 (Supplementary Material). First, the elastic modulus $G_{0}$ decreased significantly between RT112 and J82 (Figure 2A), while the slope $a$ of $G^{\prime}$ increased (Figure 2B). At a high frequency, $G_{1}$ of RT112 increased significantly as compared to T24 and J82 (Figure S1A), while the slope $b$ of $G^{\prime}$ decreased (Figure 2C). These results indicated that the less-invasive cells were more elastic. In addition, the loss modulus $G^{\prime \prime}$ exhibited a similar dependency on the cancer cell invasiveness. Indeed, the slope $c$ (Figure 2D, $8 \mathrm{kPa}$ ) of the more invasive cells J82 was lower than RT112 and T24 and close to zero, revealing that the loss modulus followed a single power law.

These results demonstrated that the cell microrheology parameters can provide the signature of malignancy, with more invasive cell lines being less elastic and more deformable, which gives them the advantage of rapidly changing their shape and migrating through endothelial barriers.

\subsection{Comparison of Various Substrates}

While the use of $8 \mathrm{kPa}$ soft gels is biologically relevant in the context of metastasis, when cancer cells are in contact with the endothelium monolayer (having a similar rigidity [27]), it is also important to investigate the effect of the substrate rigidity on the viscoelastic properties. This is relevant to understand how cancer cells modify their microstructure depending on the substrate. Here, we used polyacrylamide gels with a calibrated stiffnesses of 5-8-28 kPa. The viscoelastic moduli were measured above the cell nucleus and corrected for the effect of the substrate, as mentioned above, and the microrheological parameters were determined using Equation (3) and are summarized in Figure 2. 
These results revealed that invasive cells were sensitive to the substrate rigidity. Indeed, the rheology parameters of T24 and J82 exhibited significant changes with the gel rigidity increase. In particular, $G_{0}$ increased, while $a$ and $b$ (exponents at low and high frequencies, respectively) decreased when the substrate became more rigid (Figure 2A-C). This suggested that the cells became more rigid when the substrate was stiffer. Interestingly, the less invasive cell line RT112 did not show a similar behavior, indicating that the more invasive cells were more sensitive to the substrate rigidity. However, the effect of the substrate was less pronounced on the loss modulus. Indeed, the model revealed that the exponent $c$ of $G^{\prime \prime}$ (low frequencies) increased significantly for RT112 and J82 with the gel rigidity (Figure 2D).

Taken together, these results revealed that the mechanosensitivity of cancer cells to the substrate depended on their invasiveness.
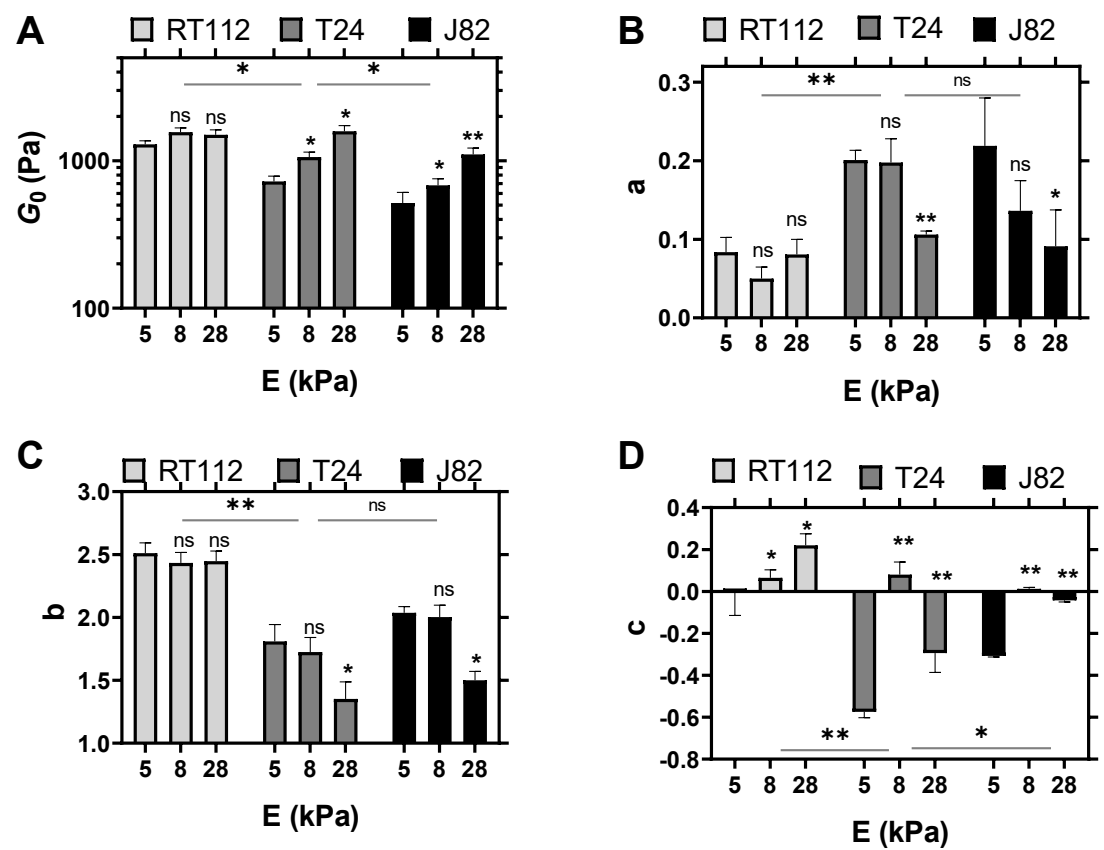

Figure 2. Parameters $G_{0}(\mathbf{A})$, exponent $a(\mathbf{B})$, exponent $b(\mathbf{C})$, and exponent $c(\mathbf{D})$ for RT112, T24, and J82 cancer cells on different gels $(E=5-8-28 \mathrm{kPa})$. The parameters were extracted from fitting averaged $G^{\prime}$ and $G^{\prime \prime}$ for each condition with Equation (3). Three different adjustments were performed, and the means of the fitted parameters were obtained. $N=5$; error bars represent the mean \pm SEM. Asterisks represent a significant difference using the Student $t$-test: $\mathrm{ns}=$ not significant, ${ }^{*} p<0.05$ and ** $p<0.01$. For each cell line, the statistical asterisk is versus the condition $5 \mathrm{kPa}$. A bar is added under the asterisk when a statistical difference is found between RT112-T24 and T24-J82 on $8 \mathrm{kPa}$ gels.

In summary, it was shown that the microrheology of cancer cells depended both on (i) the invasiveness of the cells and (ii) the substrate rigidity. These findings shed light on the adaptive power of the more invasive cell lines, which can deform and pass through barriers, but can also change their mechanical properties depending on the type of substrate.

\section{Results on Spheroids}

\subsection{Spheroid Viscoelastic Properties}

Experimental data on such spheroids are interesting and already reveal features associated with cell mechanical properties, as well as spheroid content. Figure 3 shows two sets of measurements conducted on T24 spheroids: without collagen (diameter of $320 \mu \mathrm{m}$ ) in Figure $3 \mathrm{~A}$ and with collagen at a $0.03 \mathrm{mg} / \mathrm{mL}$ concentration (diameter of $410 \mu \mathrm{m}$ ) in Figure 3B. 
There was indeed a difference with respect to the low-frequency behavior with a plateau modulus for $G^{\prime}$ and $G^{\prime \prime}$ in the case without collagen (Figure 3A), whereas interestingly, when collagen was added (Figure 3B), moduli $G^{\prime}$ and $G^{\prime \prime}$ exhibited a power law behavior with no plateau at low frequencies. Modeling of this behavior was carried out using Equation (3).

A

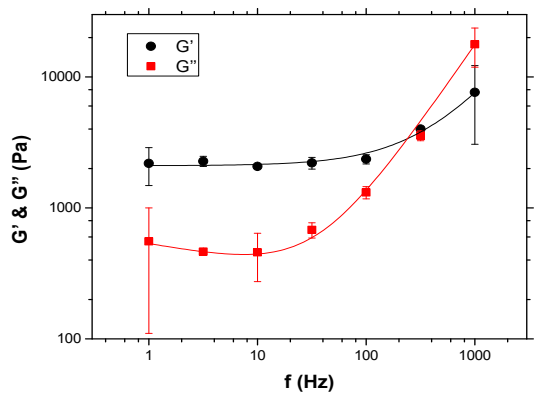

B

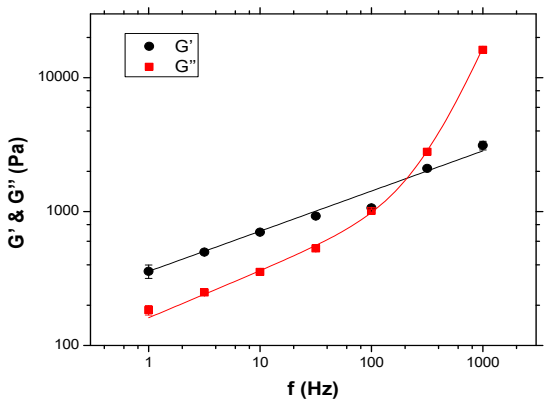

Figure 3. (A) Viscoelastic properties $\left(G^{\prime}, G^{\prime \prime}\right)$ of a T24 spheroid with no collagen. D $~ 320 \mu \mathrm{m}$. Initial number of cells $=10,000$. The lines correspond to the model in Equation (3), using $G_{0}=2100 \mathrm{~Pa}, \mathrm{a}=0$, $G_{1}=4.8 \mathrm{~Pa}, \mathrm{~b}=1.02, G_{2}=530 \mathrm{~Pa}, \mathrm{c}=-0.15, G_{3}=4.4 \mathrm{~Pa}, \mathrm{~d}=1.2$. (B) Viscoelastic properties $\left(G^{\prime}, G^{\prime \prime}\right)$ of a T24 spheroid containing collagen at $0.03 \mathrm{mg} / \mathrm{mL}$. D $\sim 410 \mu \mathrm{m}$. Initial number of cells $=10,000$. The same model gives $G_{0}=358 \mathrm{~Pa}, \mathrm{a}=0.30, \mathrm{G}_{1}=0 \mathrm{~Pa}, \mathrm{~b}=0, \mathrm{G}_{2}=161 \mathrm{~Pa}, \mathrm{c}=0.35, \mathrm{G}_{3}=0.026 \mathrm{~Pa}, \mathrm{~d}=1.92$. Representative data are shown here with $\mathrm{N}=2$ (no collagen) and $\mathrm{N}=4(0.03 \mathrm{mg} / \mathrm{mL})$; error bars represent the mean \pm SEM.

\subsection{Role of Collagen}

The role of collagen was further characterized using spheroids cultured at three different concentrations of collagen: $0-0.01 \mathrm{mg} / \mathrm{mL}$ and $0.03 \mathrm{mg} / \mathrm{mL}$. The spheroids all had an equal number of initial cells (10,000 cells) and had diameters ranging between $300 \mu \mathrm{m}$ and $410 \mu \mathrm{m}$. This ensured that the diameter would not play a role [35]. The viscoelastic properties $\left(G^{\prime}, G^{\prime \prime}\right)$ were acquired as described previously and fitted using the model in Equation (3). The fitting parameters are summarized in Figure 4 and Table 1. First, one can observe that the exponent $a$ of $G^{\prime}$ (at a low frequency) increased with the collagen concentration (Figure 4B). In particular, $a$ was null when there was no collagen. Collagen also had an effect on $G^{\prime}$ at the high frequencies, where both $G_{1}$ and $b$ decreased for the highest concentration of collagen (Figure 4A,B), suggesting that the spheroid modified its elastic properties when collagen was added to the microenvironment. Finally, we also show the effect of collagen on the loss modulus $G^{\prime \prime}$, where both exponents $c$ and $d$ (low and high frequencies) increased when collagen was present (Figure 4B).

In summary, these results demonstrated that the collagen changed the viscoelastic properties of the spheroid, in particular the low-frequency plateau modulus disappeared and gave rise to a small frequency dependence, typical of a soft glassy rheological system [45].

Finally, the effect of collagen on the spheroids' microstructure was studied using confocal microscopy. This technique allowed visualizing both labeled cells (using transfection with LifeAct GFP, $488 \mathrm{~nm}$ ) and the collagen (reflectance technique [20] at $633 \mathrm{~nm}$ ). An example in the case of $0.01 \mathrm{mg} / \mathrm{mL}$ collagen is shown in Figure 5, where cells are visible and collagen appears in between cells. Therefore, the microstructure of the spheroid relied on the ability of cells to bind to the extracellular matrix and construct a stronger network. In the first case, there was no collagen to be seen (data not shown); however, when using collagen, this provided a network to build on, and this dramatically affected the mechanical properties, as seen above in Figure 3. 
A

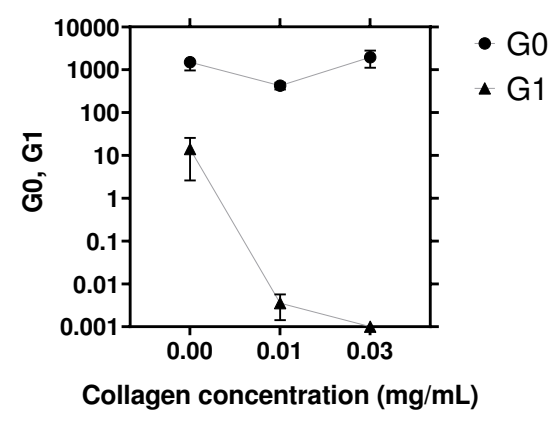

B

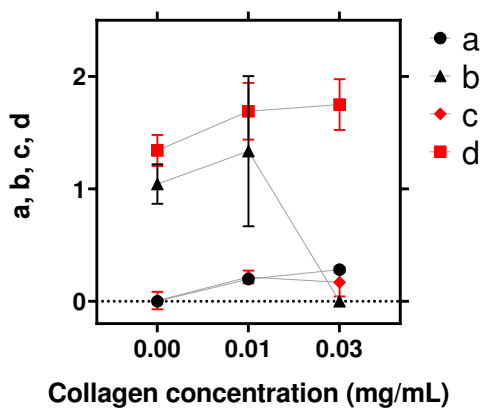

Figure 4. Role of collagen concentration $(0-0.01-0.03 \mathrm{mg} / \mathrm{mL})$ on parameters $G_{0}, G_{1}(\mathbf{A})$ and exponents $a, b, c, d(B)$. The values of all parameters are reported in Table 1. For each condition, we considered three spheroid sizes ranging from $300 \mu \mathrm{m}$ to $410 \mu \mathrm{m}$ with $G^{\prime}$ and $G^{\prime \prime}$ averaged for each spheroid diameter (a total of $\mathrm{N}=15,10,6$ experiments for respective collagen concentrations of 0 , $0.01,0.03 \mathrm{mg} / \mathrm{mL}$ ). The parameters were then extracted by fitting the averaged $G^{\prime}$ and $G^{\prime \prime}$ with the model in Equation (3). The error bars represent the standard error of the mean (SEM).

Table 1. Values of the fitting parameters of $G_{0}, a, G_{1}, b, G_{2}, c, G_{3}, d$ for different collagen concentrations $(0,0.01$ and $0.03 \mathrm{mg} / \mathrm{mL})$.

\begin{tabular}{cccc}
\hline Parameters & $\mathbf{c}=\mathbf{0}$ & $\mathbf{c}=\mathbf{0 . 0 1} \mathbf{~ m g} / \mathbf{m L}$ & $\mathbf{c}=\mathbf{0 . 0 3} \mathbf{~ g} / \mathbf{m L}$ \\
\hline$G_{0}(\mathrm{~Pa})$ & 1492 & 423 & 1946 \\
$a$ & 0 & 0.2 & 0.3 \\
$G_{1}(\mathrm{~Pa})$ & 14 & 0.004 & 0 \\
$b$ & 1 & 1.3 & 0 \\
$G_{2}(\mathrm{~Pa})$ & 364 & 197 & 1152 \\
$c$ & 0.0005 & 0.22 & 0.17 \\
$G_{3}(\mathrm{~Pa})$ & 3.6 & 0.6 & 2.8 \\
$d$ & 1.34 & 1.69 & 1.75 \\
\hline
\end{tabular}

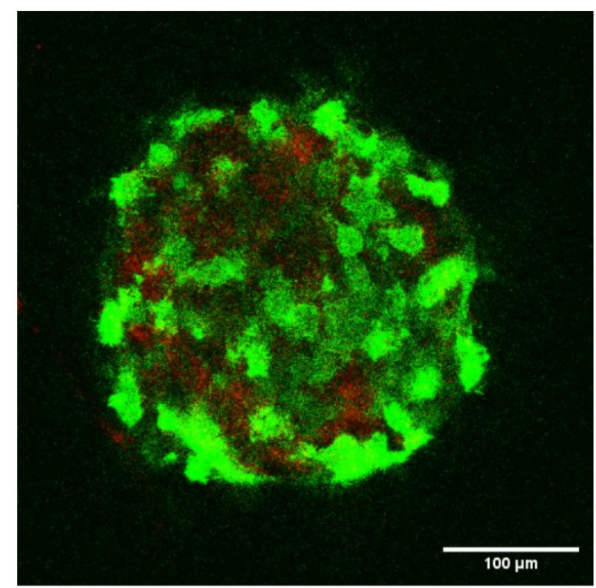

Figure 5. Confocal image of a T24 spheroid with $0.01 \mathrm{mg} / \mathrm{mL}$ collagen concentration (GFP cells in green; collagen in red). $\mathrm{D} \sim 350 \mu \mathrm{m}$.

\section{Discussion and Conclusions}

The importance of the mechanical properties of cells and tissues in relation to different physiological or pathological conditions is of utmost importance [47]. Here, we proposed to determine cell and spheroid properties using dynamic rheology thanks to AFM. The technique has already been applied successfully for cells $[5,10,27]$. However, less is known 
about the rheology of tissues; in particular, only a few biological systems have been tested for viscoelasticity so far [26,48-50], and there were no data available for spheroids, as proposed in this new study. AFM was found to be a powerful tool for measuring elastic and loss moduli $\left(G^{\prime}, G^{\prime \prime}\right)$ and revealed important new features. To analyze the data, a new model was used in Equation (3), based on the fact that the usual power law behaviors fail to describe single-cell or spheroid properties [27,46,51]. Indeed, it is common to use a single power law exponent describing the elastic modulus $G^{\prime}$ in the low-frequency regime $[10,52]$. However, the loss modulus $G^{\prime \prime}$ has a different behavior at low and high frequencies with respective small and high slopes. This can also be the case for the storage modulus $G^{\prime}$. Therefore, the model proposed here contained two potential slopes for each modulus $\left(G^{\prime}\right.$ or $G^{\prime \prime}$ ), allowing us to recover all possible cases (see Section 3.4); thus, the fitting curves (Figures 1 and 3) approximated the data very well.

The investigation of the microrheology of single cancer cells revealed that the dynamic mechanical properties are clearly dependent on cell type (i.e., invasiveness) and substrate stiffness (Figures 1 and 2). New fitting parameters using the new model suggested that possible differences between invasive or noninvasive cells can be clearly identified through the new parameters $G_{0}$ and $a$, to name just these two (see Figure 2). With respect to different substrates, cancer cells also revealed their ability to behave differently, in relation to their cytoskeleton $[27,53]$. The above parameters $G_{0}$ and $a$, as well as $c$ and $d$, were also used successfully to exhibit this microrheology evolution when the substrate stiffness increased from 5 to $28 \mathrm{kPa}$ (see Figure 2). Finally, invasive cancer cells were found to be more mechanosensitive with respect to an increase of substrate stiffness.

When treating the case of spheroids, which are known to be good tumor models $[21,24,35,54]$, interesting data were found, regarding the role of collagen or the ECM [55]. Indeed, it is known that collagen can be synthesized by cells or can be recruited from the extracellular matrix, and in particular, collagen I was found to be a good model for the microenvironment of bladder cancer cells when studying tumorigenesis [33]. Using small amounts of collagen (here, ranging from 0 to $0.03 \mathrm{mg} / \mathrm{mL}$ ), it was found that cells re-arrange efficiently in order to form a more compact structure (see Figure 5) using collagen as a proxy $[24,56]$. This resulted in various behaviors due to the viscoelastic nature of collagen [20,57]. Indeed, collagen has enhanced viscous properties at a low frequency and exhibits very small moduli (typically a few tens or hundreds of $\mathrm{Pa}$ ). This effect modified quite significantly the low-frequency behavior of the spheroids, as shown by comparing Figure 3A,B. Initial slopes of $\sim 0.3-0.35$ are found for $G^{\prime}$ and $G^{\prime \prime}$ in Figure 3B, and this was quite different from the case without collagen (Figure $3 \mathrm{~A}$ ). In the presence of collagen, the spheroid behavior became that of a glassy system, probably because cells rearranged constantly in a disordered way to try to find a stable configuration, which could occur if adhesion proteins are expressed and enhance the elastic effects at longer times (as compared to the ones used in this study). Finally, the analysis of rheological parameters (Figure 4) showed that $G_{0}$ and $a$ are quite relevant, as with single cells, but we further noticed that $G_{1}, b, c$, and $d$ can also predict such changes. Altogether, these parameters may be quite essential for investigating the microstructural evolution of spheroids in time, when considering the main interactive components such as cells, ECM, fluid, and adhesion proteins [20].

The final question relies on the ability to describe a macroscopic system (i.e., tissue level) with a constitutive equation taking into account all the components. Here, assuming that cells within the spheroid usually look more rounded, the comparison can be made with cell measurements on the nucleus. Obviously, the signature of single cells with $\left(G^{\prime}\right.$, $G^{\prime \prime}$ ) varying as power law models is persistent at the macroscopic level (spheroid), and this could be a starting point for future modeling. This is an interesting question raised by the homogenization of poroelastic media containing inclusions/cells embedded in a matrix [58]. Such studies could be very useful since both microscopic and macroscopic properties have been measured in this study. Additionally, the active behavior of cells [24] could be considered. However, this requires further investigations. 
Therefore, these results confirm the interest in AFM rheology to investigate cells and tissues; it provides mechanical parameters (or cues) to test biological samples in the time or frequency domains, possibly leading to therapeutic investigations.

Supplementary Materials: The following are available online at https:/ / www.mdpi.com/2073-440 9/10/7/1704/s1, Figure S1: Parameters G1 (A), G2 (B), G3 (C) and exponent d (D) for RT112, T24 and J82 cancer cells on different gels $(\mathrm{E}=5-8-28 \mathrm{kPa})$.

Author Contributions: Conceptualization, C.V.; methodology, Y.A., A.G., J.R., V.M.L., and C.V.; experiments, Y.A., A.G., and J.R.; data analysis, Y.A. and A.G.; writing-review and editing, Y.A., A.G., and C.V. All authors read and agreed to the published version of the manuscript.

Funding: This research used the LIPhy AFM Platform, funded by the Nanoscience foundation, Grenoble, France. The authors are members of the LabEx Tec21 (Investissements d'Avenir: Grant Agreement No. ANR-11-LABX-0030).

Data Availability Statement: Data are available from the authors upon request.

Acknowledgments: The authors are thankful to A. Duperray for fruitful discussions and for providing cancer cell lines. They also thank A. Popov for her help with the spheroids' preparation.

Conflicts of Interest: The authors declare no conflict of interest.

\section{References}

1. Lekka, M.; Laidler, P.; Gil, D.; Lekki, J.; Stachura, Z.; Hrynkiewicz, A.Z. Elasticity of normal and cancerous human bladder cells studied by scanning force microscopy. Eur. Biophys. J. 1999, 28, 312-316. [CrossRef]

2. Cross, S.E.; Jin, Y.S.; Rao, J.; Gimzewski, J.K. Nanomechanical analysis of cells from cancer patients. Nat. Nanotechnol. 2007, 2, 780-783. [CrossRef]

3. Verdier, C.; Étienne, J.; Duperray, A.; Preziosi, L. Review: Rheological properties of biological materials. C. R. Acad. Sci. Phys. 2009, 10, 790-811. [CrossRef]

4. Rother, J.; Nöding, H.; Mey, I.; Janshoff, A. Atomic force microscopy-based microrheology reveals significant differences in the viscoelastic response between malign and benign cell lines. Open Biol. 2014, 4, 140046. [CrossRef]

5. Abidine, Y.; Laurent, V.M.; Michel, R.; Duperray, A.; Verdier, C. Local mechanical properties of bladder cancer cells measured by AFM as a signature of metastatic potential. Eur. Phys. J. Plus 2015, 130, 202. [CrossRef]

6. Pollard, T.D.; Borisy, G.G. Cellular motility driven by assembly and disassembly of actin filaments. Cell 2003, 112, 453-465. [CrossRef]

7. Biot, M.A. General theory of three-dimensional consolidation. J. Appl. Phys. 1941, 12, 155-164. [CrossRef]

8. Moeendarbary, E.; Valon, L.; Fritzsche, M.; Harris, A.R.; Moulding, D.A.; Thrasher, A.J.; Stride, E.; Mahadevan, L.; Charras, G.T. The cytoplasm of living cells behaves as a poroelastic material. Nat. Mater. 2013, 12, 253-261. [CrossRef] [PubMed]

9. Abidine, Y.; Laurent, V.M.; Michel, R.; Duperray, A.; Palade, L.; Verdier, C. Physical properties of polyacrylamide gels probed by AFM and rheology. Europhys. Lett. 2015, 109, 38003. [CrossRef]

10. Alcaraz, J.; Buscemi, L.; Grabulosa, M.; Trepat, X.; Fabry, B.; Farré, R.; Navajas, D. Microrheology of human lung epithelial cells measured by atomic force microscopy. Biophys. J. 2003, 84, 2071-2079. [CrossRef]

11. Laurent, V.M.; Planus, E.; Fodil, R.; Isabey, D. Mechanical assessment by magnetocytometry of the cytosolic and cortical cytoskeletal compartments in adherent epithelial cells. Biorheology 2003, 40, 235-240.

12. Yamada, S.; Wirtz, D.; Kuo, S.C. Mechanics of living cells measured by laser tracking microrheology. Biophys. J. 2000, 78, 1736-1747. [CrossRef]

13. Guillou, L.; Dahl, J.B.; Lin, J.M.G.; Barakat, A.I.; Husson, J.; Muller, S.J.; Kumar, S. Measuring Cell Viscoelastic Properties Using a Microfluidic Extensional Flow Device. Biophys. J. 2016, 111, 2039-2050. [CrossRef] [PubMed]

14. Evans, E.; Yeung, A. Apparent viscosity and cortical tension of blood granulocytes determined by micropipet aspiration. Biophys. J. 1989, 56, 151-160. [CrossRef]

15. Hénon, S.; Lenormand, G.; Richert, A.; Gallet, F. A new determination of the shear modulus of the human erythrocyte membrane using optical tweezers. Biophys. J. 1999, 76, 1145-1151. [CrossRef]

16. Leartprapun, N.; Iyer, R.R.; Untracht, G.R.; Mulligan, J.A.; Adie, S.G. Photonic force optical coherence elastography for three-dimensional mechanical microscopy. Nat. Commun. 2018, 9, 2079. [CrossRef]

17. Fung, Y.C. Biomechanics. Mechanical Properties of Living Tissues; Springer: New York, NY, USA, 1993.

18. Iordan, A.; Duperray, A.; Verdier, C. Fractal approach to the rheology of concentrated cell suspensions. Phys. Rev. E 2008, 77, 011911. [CrossRef]

19. Preziosi, L.; Ambrosi, D.; Verdier, C. An Elasto-visco-plastic Model of Cell Aggregates. J. Theor. Biol. 2010, 262, 35-47. [CrossRef]

20. Iordan, A.; Duperray, A.; Gérard, A.; Grichine, A.; Verdier, C. Breakdown of cell-collagen networks through collagen remodeling. Biorheology 2010, 47, 277-295. [CrossRef] 
21. Delarue, M.; Montel, F.; Caen, O.; Elgeti, J.; Siaugue, J.M.; Vignjevic, D.; Prost, J.; Joanny, J.F.; Cappello, G. Mechanical Control of Cell flow in Multicellular Spheroids. Phys. Rev. Lett. 2013, 110, 138103. [CrossRef]

22. Helmlinger, G.; Netti, P.A.; Lichtenbeld, H.C.; Melder, R.J.; Jain, R.K. Solid stress inhibits the growth of multicellular tumor spheroids. Nat. Biotechnol. 1997, 15, 778-783. [CrossRef]

23. Delarue, M.; Montel, F.; Vignjevic, D.; Prost, J.; Joanny, J.F.; Cappello, G. Compressive stress inhibits proliferation in tumor spheroids through a volume limitation. Biophys. J. 2014, 107, 1821-1828. [CrossRef]

24. Dolega, M.; Zurlo, G.; Goff, M.L.; Greda, M.; Verdier, C.; Joanny, J.F.; Cappello, G.; Recho, P. Mechanical behavior of multi-cellular spheroids under osmotic compression. J. Mech. Phys. Solids 2021, 147, 104205. [CrossRef]

25. Nia, H.; Bozchalooi, I.; Li, Y.; Han, L.; Hung, H.H.; Frank, E.; Youcef-Toumi, K.; Ortiz, C.; Grodzinsky, A. High-Bandwidth AFM-Based Rheology Reveals that Cartilage is Most Sensitive to High Loading Rates at Early Stages of Impairment. Biophys. J. 2013, 104, 1529-1537. [CrossRef] [PubMed]

26. Connizzo, B.K.; Grodzinsky, A.J. Tendon exhibits complex poroelastic behavior at the nanoscale as revealed by high-frequency AFM-based rheology. J. Biomech. 2017, 54, 11-18. [CrossRef]

27. Abidine, Y.; Constantinescu, A.; Laurent, V.M.; Rajan, V.S.; Michel, R.; Laplaud, V.; Duperray, A.; Verdier, C. Mechanosensitivity of cancer cells in contact with soft substrates using AFM. Biophys. J. 2018, 114, 1165-1175. [CrossRef] [PubMed]

28. Chotard-Ghodsnia, R.; Haddad, O.; Leyrat, A.; Drochon, A.; Verdier, C.; Duperray, A. Morphological analysis of tumor cell/endothelial cell interactions under shear flow. J. Biomech. 2007, 40, 335-344. [CrossRef] [PubMed]

29. Haddad, O.; Chotard-Ghodsnia, R.; Verdier, C.; Duperray, A. Tumor cell/endothelial cell tight contact upregulates endothelial adhesion molecule expression mediated by NFkB: Differential role of the shear stress. Exp. Cell Res. 2010, 316, 615-626. [CrossRef]

30. Laurent, V.M.; Duperray, A.; Sundar, V.R.; Verdier, C. Atomic Force Microscopy Reveals a Role for Endothelial Cell ICAM-1 Expression in Bladder Cancer Cell Adherence. PLoS ONE 2014, 9, e98034. [CrossRef]

31. Rajan, V.S.; Laurent, V.M.; Verdier, C.; Duperray, A. Unraveling the Receptor-Ligand Interactions between Bladder Cancer Cells and the Endothelium Using AFM. Biophys. J. 2017, 112, 1246-1257. [CrossRef]

32. Riedl, J.; Crevenna, A.H.; Kessenbrock, K.; Yu, J.H.; Neukirchen, D.; Bista, M.; Bradke, F.; Jenne, D.; Holak, T.A.; Werb, Z.; et al. Lifeact: A versatile marker to visualize F-actin. Nat. Methods 2008, 5, 605-607. [CrossRef]

33. Qiu, Y.; Qiu, S.; Deng, L.; Nie, L.; Gong, L.; Liao, X.; Zheng, X.; Jin, K.; Li, J.; Tu, X.; et al. Biomaterial 3D collagen I gel culture model: A novel approach to investigate tumorigenesis and dormancy of bladder cancer cells induced by tumor microenvironment. Biomaterials 2020, 256, 120217. [CrossRef] [PubMed]

34. Friedl, P.; Borgmann, S.; Bröcker, E.B. Amoeboid leukocyte crawling through extracellular matrix: Lessons from the Dictyostelium paradigm of cell movement. J. Leukoc. Biol. 2001, 70, 491-509. [PubMed]

35. Giannetti, A.; Revilloud, J.; Verdier, C. Mechanical properties of 3D tumor spheroids measured by AFM. Comput. Methods Biomech. Biomed. Eng. 2020, 23, S125-S127. [CrossRef]

36. Butt, H.J.; Jaschke, M. Calculation of thermal noise in atomic force microscopy. Nanotechnology 1995, 6, 1-7. [CrossRef]

37. Sneddon, I.N. The relation between load and penetration in the axisymmetric Boussinesq problem for a punch of arbitrary profile. Int. J. Eng. 1965, 3, 47-57. [CrossRef]

38. Alcaraz, J.; Buscemi, L.; de Morales, M.P.; Colchero, J.; Baro, A.; Navajas, D. Correction of Microrheological Measurements of Soft Samples with Atomic Force Microscopy for the Hydrodynamic Drag on the Cantilever. Langmuir 2002, 18, 716-721. [CrossRef]

39. Dimitriadis, E.K.; Horkay, F.; Maresca, J.; Kachar, B.; Chadwick, R.S. Determination of elastic moduli of thin layers of soft material using the atomic force microscope. Biophys. J. 2002, 82, 2798-2810. [CrossRef]

40. Santos, J.A.C.; Rebêlo, L.M.; Araujo, A.C.; Barrosa, E.B.; de Sousa, J.S. Thickness-corrected model for nanoindentation of thin films with conical indenters. Soft Matter 2012, 8, 4441-4448. [CrossRef]

41. Vichare, S.; Sen, S.; Inamdar, M.M. Cellular mechanoadaptation to substrate mechanical properties: Contributions of substrate stiffness and thickness to cell stiffness measurements using AFM. Soft Matter 2014, 10, 1174-1181. [CrossRef]

42. Rheinlaender, J.; Dimitracopoulos, A.; Wallmeyer, B.; Kronenberg, N.M.; Chalut, K.J.; Gather, M.C.; Betz, T.; Charras, G.; Franze, K. Cortical cell stiffness is independent of substrate mechanics. Nat. Mater. 2020, 19, 1019-1025. [CrossRef]

43. Korsunsky, A.M.; Constantinescu, A. Work of indentation approach to the analysis of hardness and modulus of thin coatings. Mater. Sci. Eng. Part A 2006, 423, 28-35. [CrossRef]

44. Palade, L.I.; Vernay, V.; Attané, P. A modified fractional model to describe the entire viscoelastic behavior of polybutadienes from flow to glassy regime. Rheol. Acta 1996, 35, 265-273. [CrossRef]

45. Sollich, P.; Lequeux, F.; Hébraud, P.; Cates, M.E. Rheology of Soft Glassy Materials. Phys. Rev. Lett. 1997, 78, 2020-2023. [CrossRef]

46. Stamenovic, D.; Rosenblatt, N.; Montoya-Zavala, M.; Matthews, B.D.; Hu, S.; Suki, B.; Wang, N.; Ingber, D.E. Rheological behavior of living cells is timescale-dependent. Biophys. J. 2007, 93, L39-L41. [CrossRef] [PubMed]

47. Denis Wirtz, K.K.; Searson, P.C. The physics of cancer: The role of physical interactions and mechanical forces in metastasis. Nat. Rev. Cancer 2011, 11, 512-522. [CrossRef] [PubMed]

48. Nia, H.; Han, L.; Li, Y.; Ortiz, C.; Grodzinsky, A. Poroelasticity of Cartilage at the Nanoscale. Biophys. J. 2011, 101, $2304-2313$. [CrossRef] [PubMed]

49. Chiron, S.; Tomczak, C.; Duperray, A.; Laine, J.; Bonne, G.; Eder, A.; Hansen, A.; Eschenhagen, T.; Verdier, C.; Coirault, C. Complex Interactions between Human Myoblasts and the Surrounding 3D Fibrin-Based Matrix. PLoS ONE 2012, 7, e36173. [CrossRef] 
50. Connizzo, B.K.; Naveh, G.R.S. In situ AFM-based nanoscale rheology reveals regional non-uniformity in viscoporoelastic mechanical behavior of the murine periodontal ligament. J. Biomech. 2020, 111, 109996. [CrossRef]

51. de Sousa, J.S.; Freire, R.S.; Sousa, F.D.; Radmacher, M.; Silva, A.F.B.; Ramos, M.V.; Monteiro-Moreira, A.C.O.; Mesquita, F.P.; Moraes, M.E.A.; Montenegro, R.C.; et al. Double power law viscoelastic relaxation of living cells encodes motility trends. Sci. Rep. 2020, 10, 4749. [CrossRef]

52. Lenormand, G.; Bursac, P.; Butler, J.P.; Fredberg, J.J. Out-of-equilibrium dynamics in the cytoskeleton of the living cell. Phys. Rev. E 2007, 76, 041901. [CrossRef] [PubMed]

53. Solon, J.; Levental, I.; Sengupta, K.; Georges, P.C.; Janmey, P.A. Fibroblast adaptation and stiffness matching to soft elastic substrates. Biophys. J. 2007, 93, 4453-4461. [CrossRef]

54. Dolega, M.E.; Delarue, M.; Ingremeau, F.; Prost, J.; Delon, A.; Cappello, G. Cell-like pressure sensors reveal increase of mechanical stress towards the core of multicellular spheroids under compression. Nat. Commun. 2017, 8, 14056. [CrossRef]

55. Elosegui-Artola, A. The extracellular matrix viscoelasticity as a regulator of cell and tissue dynamics. Curr. Opin. Cell Biol. 2021, 72, 10-18. [CrossRef]

56. Dolega, M.E.; Monnier, S.; Brunel, B.; Joanny, J.F.; Recho, P.; Cappello, G. Extracellular matrix in multicellular aggregates acts as a pressure sensor controlling cell proliferation and motility. eLife 2021, 10, e63258. [CrossRef] [PubMed]

57. Vader, D.; Kabla, A.; Weitz, D.; Mahadevan, L. Strain-induced alignment in collagen gels. PLoS ONE 2009, 4, e5902. [CrossRef] [PubMed]

58. Royer, P.; Recho, P.; Verdier, C. On the quasi-static effective behaviour of poroelastic media containing elastic inclusions. Mech. Res. Commun. 2019, 96, 19-23. [CrossRef] 